\title{
PENGARUH KEPEMIMPINAN DAN LOYALITAS TERHADAP KINERJA PEGAWAI DI PT PLN UID JAWA TIMUR
}

\author{
Renaldi Yayang Gustara, Mei Retno Adiwati \\ Program Studi Manajemen, Fakultas Ekonomi dan Bisnis, \\ Universitas Pembangunan Nasional "Veteran" Jawa Timur \\ E-mail: renaldigustara@gmail.com
}

\begin{abstract}
This research aims to find out the Influence of Leadership and Loyalty on Employee Performance at PT PLN UID East Java. Data collection methods include check lists, questionnaires, interview guidelines, to cameras for photos or to record images. In this case the method of collecting data through questionnaires by spreading questionnaires to employees of PT PLN UID JATIM. Modeling in the analysis of this study is to use PLS. The results showed that leadership styles that give a very good influence in improving employee performance, as well as employee loyalty have an influence in improving performance. The conclusion of this study is that employees will easily excel and easily improve their performance if the leadership or manager has a good nature, firm and not arbitrary towards employees. Meanwhile, employees who have high loyalty to the company will automatically improve performance directly.
\end{abstract}

Keywords: Influence of Leadership, Loyalty, Employee Performance

\section{PENDAHULUAN}

Satu-satunya penjual jasa listrik di Indonesia adalah PLN. Dalam pelayanan pendistribusian kelistrikan PLN membagi-bagi fungsi unit induknya kedalam beberapa unit induk berdasarkan pada sistem tenaga listrik yaitu pembangkitan, transmisi, dan distribusi. Selain itu ada juga unit induk atau pusat-pusat lain sebagai penunjang berlangsungnya perusahaan. Karena luasnya cakupan wilayah kerja PLN, maka PLN memiliki unit-unit di seluruhnwilayah Indonesia yang mempunyai fungsi masing-masing sesuai dengan unit induknya.

Tabel 1 Data Target Dan Realissi Pemasangan Meteran Baru

\begin{tabular}{|c|c|c|c|}
\hline Tahun & Target & Realisasi & Persentasi Realisasi \\
\hline 2017 & 104.235 pelanggan & 105.660 pelanggan & $1 \%$ \\
\hline 2018 & 105.660 pelanggan & 104.500 pelanggan & $-1 \%$ \\
\hline 2019 & 104.500 pelanggan & 104.756 pelanggan & $2 \%$ \\
\hline
\end{tabular}

Dari data diatas dilihat bahwa PT.PLN UID Jawa Timur pada tahun 2017 terdapaat 105.660 pelanggan di provinsi jawa timur melakukan pemaasangan baru meteran listrik. Hal ini jauh melebihi dari target tahun 2017 sebesar 104.235 pelanggan. Pada tahun 2018 terdapat 104.500 pelanggan yang melakukan pemasakan baru meteran listrik. Hal ini kurang dari target tahun 2018 sebesar 104.500 pelanggan. Tahun 2019 terdapat 104.756 pelanggan yang memasang meteran listrik baru hal ini meningkat daripada tahun 2018 sebesar 2\%. Hasil diatas menunjukkan bahwa peningkatan jumlah realisasi pada tahun 2017 dan 2019 menunjukan 
indikasi bahwa terdapat indikasi peningkatan kinerja. Pada tahun 2018 mengalami penurunan jumlah pelangggan hal ini menunjukan bahwa terdapat penurunan kinerja.

Fenomena yang ditemukan peneliti menunjukkan bahwa secara interferensial gaya kepemimpinan dan loyalitas karyawa mempunyai pengaruh terhadap kinerja pegawai di PLN UID Jawa Timur.

Tabel 2 Data Trunover karyawan

\begin{tabular}{|c|c|c|c|c|c|}
\hline Tahun & $\begin{array}{c}\text { Jumlah } \\
\text { Karyawan } \\
\text { Awal } \\
\text { Tahun }\end{array}$ & $\begin{array}{c}\text { Jumlah Karyawan } \\
\text { Yang } \\
\text { Keluar/mutasi }\end{array}$ & $\begin{array}{c}\text { Jumlah Karyawan } \\
\text { YangMasuk }\end{array}$ & $\begin{array}{c}\text { Jumlah } \\
\text { Karyawan Akhir } \\
\text { Tahun }\end{array}$ & $\begin{array}{c}\text { Trunov er } \\
\text { Rate }\end{array}$ \\
\hline 2017 & 219 & 40 & 10 & 189 & $15 \%$ \\
\hline 2018 & 189 & 28 & 25 & 186 & $2 \%$ \\
\hline 2019 & 186 & 30 & 18 & 174 & $7 \%$ \\
\hline
\end{tabular}

Diketahui trunover rate karyawan yang diperoleh pada tahun 2017 kenaikan trunover sebesar 15\%. Pada tahun 2018 trunover menglami perunuan sebessar 2\% dan pada tahun 2019 mulai mengalami kenaikan kembali 7\%. Dari pengaruh data trunover yang mengalami kenaikan dan penurunan menjadi fenomena yang akan menjelaskan apakah kepemimpinan daan loyalitas berpengaruh terhadap kinerja pegawai di PLN UIDJawa Timur.

Berdasarkan dari wawancara secara singkat dari pihak PLN yang diberikan kepada peneliti permasalahan kepemimpinan yang terjadi didalam perusahaan. Pemimpinan yang berjiwa rendah hati dan mendengaarkan keluhan dari pegawaai yang berorientasi kepada hasil yang maksimal lebih disukai oleh para pegawai. Pegawai kurang menyukai pemimpin yang bersikap otoriter dan marah-marah jika hasilnya tidak maksimal. Namun, perbedaan pandangan ini terdapat karyawan yang menyukai pemimpin yang ototriter karena dianggap tegas dibanding pemimpin yang santai dengan hasil maksimal. Dari perbedaan pandangan ini pula mucul fenonema yang menjadi fokus penelitaian apakah kepemimipian dan loyalitas berpengaruh terhadap kinerja pegawai didalam perusahaan.

Berdasarkan mini riset yang peneliti lakukan diketahui bahwa 51,6\% tidak pernahmelakukan absen dan $48,4 \%$ pernah melakukan absen. Hal ini menunjukan bahwaterdapat karyawan yang kurang memiliki kesadaran akan kesetiaan terhadap perusahaan. Terdapat 67,7\% mengatakan bahwa prestasi penting untuk suatu perkerjaan dan 32,3\% mengatakan bahwa prestasi tidak penting dalam suatu perkerjaan. Didalam PT PLN UID JATIM masih terdapat karyawan yang menganggap bahwa prestasi kurang penting. Karyawan lebih mengganggap berkerja sesuai kemampuan yang lebih penting dibanding dengan prestasi sehingga mengakibatkan kinerja dari karyawan tersebut tidak meningkat. Selain itu, terdapat $90.3 \%$ karyawan yang memiliki kompetensi dalam perusahaan. Kompetensi dalam perusahaan ini mendorong terciptanya kinerja karyawan. Para karyawan ini sehingga mudah mendapatkan kenaikan jabatan dan terdapat 9,7\% kurang memiliki kompetensi dalam perusahaan. Hal ini dibuktikan dengan terdapat karyawan yang menggangap yang terciptanya ide cuman dari pimpinanan dan karyawan tidak berhak untuk mengeluarkan ide.

Menurut penelitian (Letsoin \& Ratnasari, 2020) bahwa loyalitas berpengaruh terhadap kinerja karyawan. (Marjaya \& Pasaribu, 2019) bahwa kepemimpinan berpengaruh terhadap kinerja karyawan. Menurut penelitian (Rosalina \& Wati, 2020) bahwa kepemimpinan tidak 
berpengaruh terhadap kinerja karyawan. Menurut (Basna, 2016) bahwa loyalitas tidak berpengaruh terhadap kinerja karyawan.

Dari fenomena dan gap riset data pendukung peneliti tertarik meneliti kembali faktor-faktor yang memengaruhi kinerja karyawan pada PT PLN UID JATIM. Penelitian ini terdapat variabel bebas kepemimpinan, loyalitas, kompetensi sedangkan untuk variabel terikat yaitu kinerja karyawan. Dari permasalahan yang terjadi maka peneliti akan meneliti kembali "Pengaruh Kepemimpinan dan Loyalitas Terhadap Kinerja Pegawai di PT PLN UID Jawa Timur”

\section{KAJIAN PUSTAKA}

\section{Manajemen Sumber Daya Manusia}

Menurut (Hasibuan \& Hasibuan, 2016), manajemen sumber daya manusia merupakan pemanfaatan sejumlah individu untuk mencapai tujuan organisasi. Menurut (Haikal, 2017) "Manajemen personalia diperlukan untuk meningkatkan efektivitas sumber daya manusia dalam organisasi. Tujuannya adalah untuk memberikankepada organisasi satuan kerja yang efektif"

\section{Kepemimpinan}

Kepemimpinan ialah sebuah kemampuan atau kekuatan dalam diriseseorang untukmem impin serta mempengaruhi orang lain dalam bekerja dengan tujuan untuk mencapai target yang ditentukan. Gaya kepemimpinan ini pada umumnya dapat ditemukan pada kantor/ instani pemerintahan dan perusahaan besar yang telah mempunyai budaya organisasi yang kuatsejak lama.

\section{Loyalitas}

Loyalitas kerja ditunjukkan dengan sikap yang dimiliki karyawan untuk bersedia memberikan segala kemampuan, pikiran, ketrampilan dan keahlian yang dimiliki demi mencapai tujuan perusahaan, melaksanakan tugas dengan tanggung jawab, disiplin, dan jujurdalam bekerja, ikut menjaga segala rahasia perusahaan, dan berperilaku setia pada perusahaan untuk tidak berpindah ke perusahaan lain.

\section{Kinerja Pegawai}

Kinerja (prestasi kerja) adalah hasil kerja secara kualitas dan kuantitas yang dicapai oleh seorang pegawai dalam melaksanakan fungsinya sesuai dengan tanggungjawab yang diberikan kepadanya. Performance atau kinerja merupakan hasil atau kluaran dari suatu proses (Nurlaila, 2010).

\section{Hubungan Antar Variabel}

\section{Pengaruh Kepemimpinan Terhadap Kinerja}

Penelitian oleh (Ahmadi \& Sulistyono, 2019) Hal menyatakan bahwa kepemimpinan memiliki pengaruh terhadap kinerja karyawan. Semakin baik tingkat pengaruh pimpinan maka semakin cepat dan baik karyawan meningkatkan kinerjanya.

Penelitian (Ramadhany, 2017) menyatakan bahwa kepemimpinan berpengaruh positif terhadap kinerja karyawan. Hasil ini menunjukan jika pengaruh pimpinan baik maka karyawan nyaman untuk berkerja sehingga kinerja dapat meningkat.

Landasan teori variabel kepemimpinan yang mempengaruhi kinerja karyawan. menjelaskan pemahaman kepemimpinan terhadap kinerja dan kemudian menarik kesimpulan apa yang mendasari atau melatarbelakangi perilaku tersebut. Sehingga karyawan dapat memahami 
pentingnya kepemimpinan kemudian dapat menjadikan sebagai pengaruh untuk peningkatan kinerja. Berdasarkan hasil penelitian sebelumnya, maka logika berpikir yang dapat dibentuk adalah semakin baik pengaruh kepemimpinan karyawan maka kinerja karyawan semakin cepat untuk maksimal.

\section{Pengaruh loyalitas terhadap kinerja karyawan}

Penelitian (Letsoin \& Ratnasari, 2020) menunjukan bahwa loyalitas memiliki pengaruh terhadap kinerja karywan. Tingkat loyalitas karyawan dapat mencerminkan bahwa karywan tersebut menyukai pekerjaannya sehingga karyawan akan merasa bersemangat untuk mrningkatkan kinerjanya.

Landasan teori yang variabel loyalitas yang mempengaruhi kinerja karyawan. Menjelaskan pemahaman loyalitas terhadap kinerja, dan kemudian menarik kesimpulan apa yang mendasari atau melatarbelakangi perilaku tersebut. Sehingga karyawan dapat memahami pentingnya loyalitas kerja kemudian dpat menjadikan sebagai peningkatan kinerja karyawan. Berdasarkan hasil penelitian sebelumnya, maka logika berpikir yang dapat dibentuk adalah semakin baik loyalitas karywan maka akan menghasilkan proses untuk peningkatan kinerja karyawan.

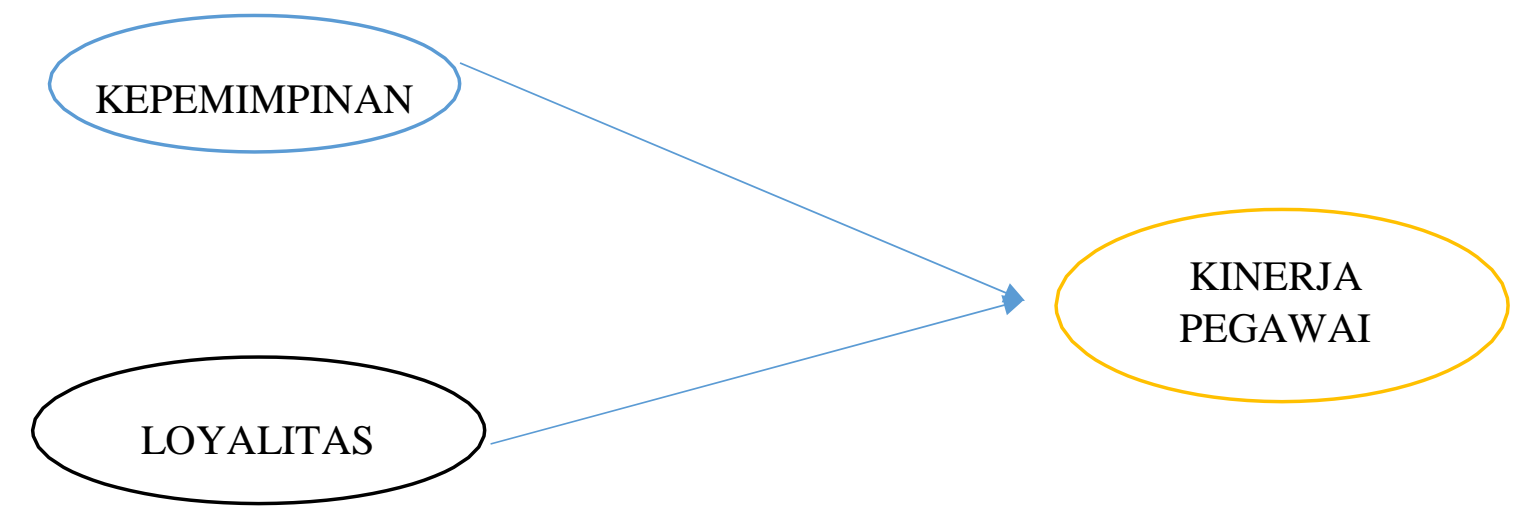

\section{Hipotesis}

Gambar 1. Kerangka Berfikir

Hipotesis pada penelitian ini diantaranya:

H1: kepemimpinan berpengaruh positif terhadap kinerja pegawai

$\mathrm{H} 2$ : loyalitas kerja berpengaruh positif terhadap kinerja pegawai

\section{METODE PENELITIAN}

Populasi penelitian sebanyak 186 karyawan PT PLN UID JATIM. Dengan persentase kelonggaran untuk kesalahan 10\% maka didapatakan sampel untuk penelitian sebesar 68 karyawan PT PLN UID JATIM dengan menggunakan random sampling.

Metode pengumpulan data berupa check list, kuesioner, pedoman wawancara, hingga kamera untuk foto untuk merekam gambar. Dalam hal ini metode pengumpulan datanyamelalui kuisioner dengan menyebar angket kepada karyawan PT PLN UID JATIM. Permodelan dalam analisis penelitian ini dengam program smartPLS 3.0 yang merupakan metode analisis yang power full, karena tidakdidasarkan pada banyak asumsi (Ghozali, 2013).

Pengujiaan hipotesis dilakukan dengan metode resampling bootstraping. Statistik uji yang digunakan yakni T-Statistics atau Uji Path Coefficient. Pengujian hipotesis dalam penelitian ini 
dilakukan dengan melihatnilai dari T-Statistics dan P-Values, dengan dasar pengambilan keputusan sebagai berikut:

1) Jika nilai $T$-Statistic lebih dari $T$-Tabel dengan nilai $P$-Values kurang dari $0,05(\mathrm{P}<0,05)$ maka hipotesis dinyatakan diterima.

2) Jika T-Statistic kurang dari T-Tabel dengan nilai P-Values lebih dari $0,05(\mathrm{P}>0,05)$ maka hipotesis dinyatakan ditolak

\section{HASIL DAN PEMBAHASAN}

3.1. Hasil

\subsubsection{Deskripsi Karakteristik Responden}

Penelitian inidilakukan dengan menyebarkan angket sebanyak 65 angket melalui google form yang disebar lewat media sosial. Hal ini dikarena sesuai dengan sampel yang peneliti ambil yaitu 65 responden.

Tabel 3. Karakteristik Responden Berdasarkan Kelompok Umur

\begin{tabular}{|c|c|c|}
\hline Kelompok Umur & Total & Persentasi \\
\hline 20-25 tahun & 23 & $36 \%$ \\
\hline 26-30 tahun & 26 & $39 \%$ \\
\hline 31-35 tahun & 8 & $13 \%$ \\
\hline 36-40 tahun & 5 & $7 \%$ \\
\hline 45-50 tahun & 2 & $2 \%$ \\
\hline > 50 tahun & 1 & $1 \%$ \\
\hline
\end{tabular}

Sumber: Data diolah, 2021

Diketahui dari diagram diatas bahwa kelompok umur 26 sampai 30 tahun melebihi dari sampel. hal ini memnunjukan bahwa tingkat usia produktif pada PT PLN UID JATIM sangatlah dominan. Tingkat usia produktif membuktikan bahwa semakin banyaknya usiaproduktif semakin tinggi pula tingkat kinerja yang akan dihasilkan. Dari diagram diatas juga diketahui bahwa usia 31 sampai 35 tahun sebesar $13 \%$, usia 36 ampai 40 tahun sebesar 7\%, 40 sampai 50 tahun sebesar $2 \%$, dan usia lanjut masa purna diatas 50 tahun sebesar $1 \%$.

Tabel 4. Karakteristik Responden Berdasarkan Gender

\begin{tabular}{|c|c|c|}
\hline gender & total & persentasi \\
\hline Laki- laki & 35 & $52 \%$ \\
\hline Perempuan & 30 & $45 \%$ \\
\hline
\end{tabular}

Sumber: Data diolah, 2021

Dapat diketahui bahwa dari 65 responden, dengan rincian karyawan sebanyak 37 orang $(54 \%)$ berjenis kelamin laki-laki dan rincian karyawan sebanyak 32 orang (46\%) berjenis kelamin perempuan. Berdasarkan pengolahan data tersebut, dapat disimpulkan bahwa sebagian besar (54\%) responden berjenis kelamin laki-laki. 


\subsubsection{Evaluasi Model Pengukuran (Outer Model)}

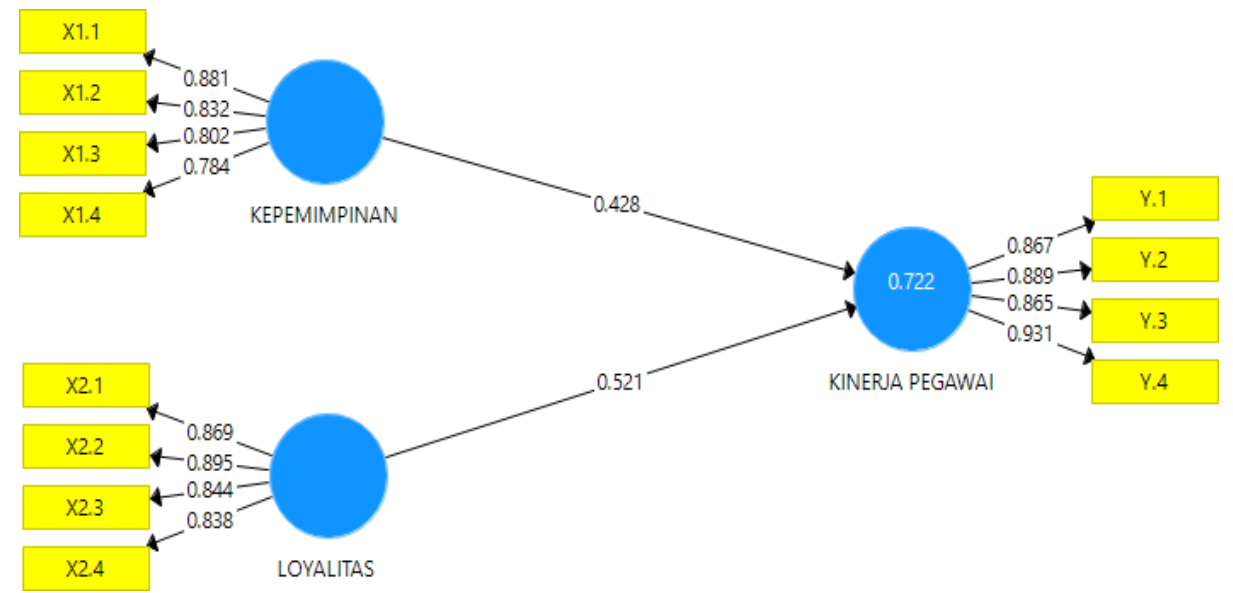

Gambar 2 Model Pengukuran (Outer Model)

Sumber: Data diolah, 2021

Tabel 5 Model Pengukuran (Outer Model)

\begin{tabular}{|c|c|c|c|}
\hline & Kepemimpinan & Kinerja pegawai & loyalitas \\
\hline X1.1 & 0,881 & & \\
\hline X1.2 & 0,832 & & \\
\hline X1.3 & 0,802 & & \\
\hline X1.4 & 0,784 & & 0,869 \\
\hline X2.1 & & & 0,895 \\
\hline X2.2 & & & 0,844 \\
\hline X2.3 & & & 0,838 \\
\hline X2.4 & & 0,867 & \\
\hline Y.1 & & 0,889 & \\
\hline Y.2 & & 0,865 & \\
\hline Y.3 & & 0,931 & \\
\hline Y.4 & & & \\
\hline
\end{tabular}

Sumber: Data diolah, 2021

Berdasarkan pengelolaan datadengan menggunakan SmartPLS 3.0 pada loading factor tidak menunjukan indikator berwarna merah atau tidak valid. Semua Indikator yang berwarna hijau atau tersebut memiliki nilai diatas 0,7 . Hal ini menandakan indikator tersebut telah memenuhi kriteria batas minimal pengukuran. Dengan demikian indikatortersebut tidak dilakukan kembali pengelolahan data ditahap kedua

\subsubsection{Evaluasi Model Struktural (Inner Model)}

R square 1 untuk kinerja (Y) sebesar 0,722 yang artinya variabel Kinerja Pegawai (Y) dapat diprediksi oleh dua variabel kepemimpian (X1), Loyalitas (X2) memiliki pengaruh 0,722 atau 72\%. Sehingga dapat disimpulkan bahwa $\mathrm{R}$ square memiliki pengaruh kuat antara variabel eksogen dan endogen. 
Berikut hasil dari bootstraping untuk menilai pengaruh indikator dengan T-Statistik

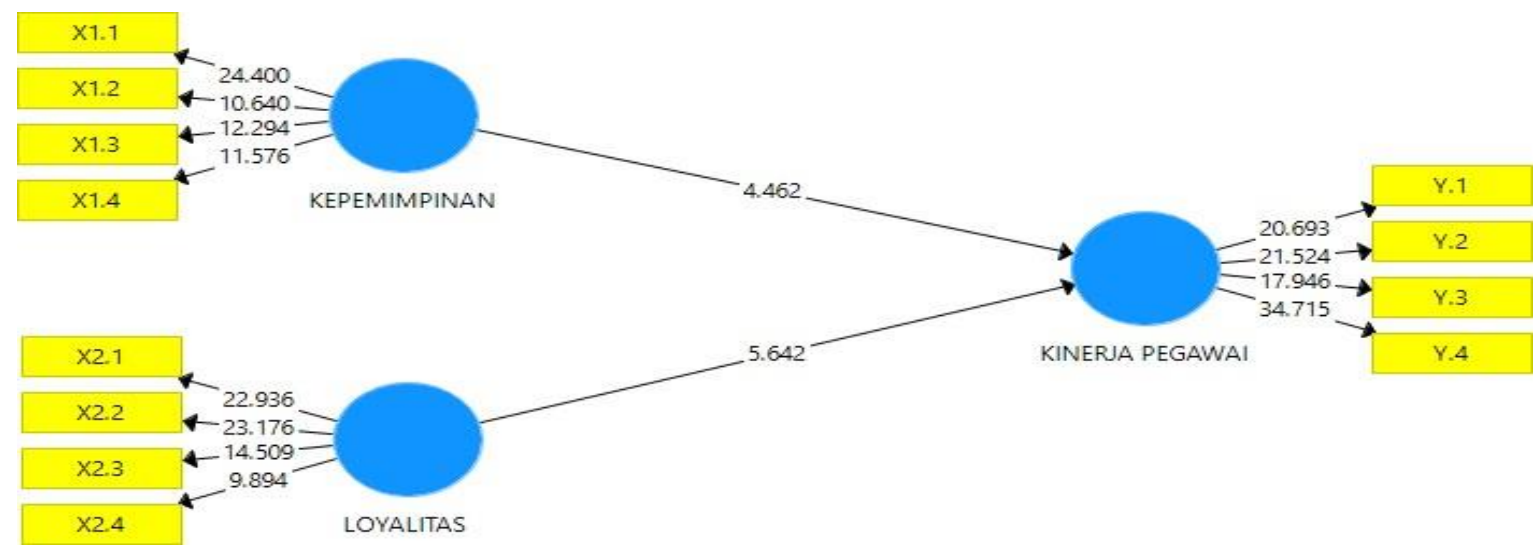

Gambar 3 Model Struktural (Inner Model)

Sumber: Data diolah, 2021

Tabel 6 Model Struktural (Inner Model)

\begin{tabular}{|c|c|c|c|c|c|}
\hline & $\begin{array}{c}\text { Sampel asli } \\
(\mathrm{O})\end{array}$ & $\begin{array}{c}\text { rata- rata } \\
\text { sampel } \\
(\mathrm{M})\end{array}$ & $\begin{array}{c}\text { standar } \\
\text { deviasi } \\
(\mathrm{STDEV})\end{array}$ & $\begin{array}{c}\text { T statistik } \\
(\text { IO/STDEVI })\end{array}$ & P Value \\
\hline $\mathrm{X} 1.1<=$ Kepemimpinan & 0,881 & 0,88 & 0,035 & 24,846 & 0 \\
\hline $\mathrm{X} 1.3<=$ Kepemimpinan & 0,802 & 0,786 & 0,066 & 12,09 & 0 \\
\hline $\mathrm{X} 1.4<=$ Kepemimpinan & 0,784 & 0,773 & 0,072 & 10,943 & 0 \\
\hline $\mathrm{X} 2.1<=$ loyalitas & 0,869 & 0,869 & 0,038 & 22,703 & 0 \\
\hline $\mathrm{X} 2.2<=$ loyalitas & 0,895 & 0,894 & 0,035 & 25,224 & 0 \\
\hline $\mathrm{X} 2.3<=$ loyalitas & 0,844 & 0,834 & 0,056 & 15,197 & 0 \\
\hline $\mathrm{X} 2.4<=$ loyalitas & 0,838 & 0,825 & 0,079 & 10,65 & 0 \\
\hline $\mathrm{Y} .1<=$ kinerja pegawai & 0,867 & 0,864 & 0,041 & 21,11 & 0 \\
\hline Y.2<= kinerja pegawai & 0,889 & 0,882 & 0,038 & 23,621 & 0 \\
\hline Y.3<=kinerja pegawai & 0,865 & 0,861 & 0,044 & 19,789 & 0 \\
\hline Y.4<=kinerja pegawai & 0,931 & 0,927 & 0,026 & 35,402 & 0 \\
\hline
\end{tabular}

Sumber: Data diolah, 2021

Berdasarkan hasil dari outer loading melalui bootstrapping dengan $\mathrm{T}$ tabel (1.996).Maka t statistik hasil bootstrapping telah memenuhi syarat validitas. Hal ini dbuktikan dengan $\mathrm{T}$ statistiknya lebih dari T tabel. 
Tabel 7 bootstrapping

\begin{tabular}{|c|c|c|c|c|c|}
\hline & $\begin{array}{l}\text { Sampel } \\
\operatorname{asli}(\mathrm{O})\end{array}$ & $\begin{array}{c}\text { rata-rata } \\
\text { sampel }(\mathrm{M})\end{array}$ & $\begin{array}{c}\text { standar deviasi } \\
\text { (STDEV) }\end{array}$ & $\begin{array}{c}\text { T statistik } \\
\text { ( IO/STDEV I) }\end{array}$ & $\begin{array}{c}\mathrm{P} \\
\text { Value }\end{array}$ \\
\hline $\begin{array}{l}\text { Kepemimpinan } \\
\text { kinerja pegawai }\end{array}$ & 0,428 & 0,420 & 0,097 & 4,400 & 0,000 \\
\hline $\begin{array}{|lll|}\text { loyalitas } & \rightarrow> & \text { kinerja } \\
\text { Pegawai } & & \\
\end{array}$ & 0,521 & 0,530 & 0,093 & 5,597 & 0,000 \\
\hline
\end{tabular}

Sumber: Data diolah, 2021

\subsection{Pembahasan}

\subsubsection{Kepemimpinan berpengaruh terhadap kinerja pegawai}

Berdasarkan hasil dari pengelolaan data melalui outer dan inner model sebagaimana yang ditunjukan dalam tabel uji hubungan variabel antar konstruk dapat disimpulkan bahwa kepemimpinan bepengaruh signifikan terhadap kinerja pegawai. Hal ini dibukktikan $\mathrm{P}$ value $<0,05$ (0.000), T Statistik > T Tabel $(4,400>1.996)$.

Diterimanya hipotesis pertama yaitu kepemimpinan berpengaruh signifikan terhadap kinerja pegawai. Tingkat gaya kepemimpinan dapat membentuk semangat kerja pegawai guna meningkatkan kinerjanya. Tipe kepemimpinan yang berorientasi pada tujuan dan sering memotivasi pegawai lebih disukai oleh para pegawai. Dibanding dengan sebaliknya jika pimimpin berlaku semena-mena maka pegawai akan sulit untuk meningkatkan kinerjanya.

Dalam hal ini mendukung penelitian dari (Marjaya \& Pasaribu, 2019) yang mengatakan bahwa kepemimpinan berpengaruh terhadap kinerja karyawan. Pemimpinan merupakan salah satu ujung tombak dalam peningkatan kinerja. Jika pemimpin berkompeten dalam mencapai hasil dan tujuan maka karyawan otomatis akan meningkatkan kinerjanya. Jika pemimpin tidak berkompeten maka karyawan akan merasa jenuh dan akhirnya tidak meningkatkan kinerjanya.. Penelitian ini juga selaras dengan Penelitian dari (Ashori, 2020) mengatakan bahwa kepemimpinan berpengaruh terhadap kinerja pegawai. Pimipinan memberikan pengaruh terhadap kinerja karyawannya. Pimpinan yang mempunyai kepemimpinan yang baik akan dapat meningkatkan kinerja bahwahannya.

\subsubsection{Loyalitas Berpengaruh Terhadap Kinerja Pegawai}

Berdasarkan hasil dari pengelolaan data melalui outer dan inner model sebagaimana yang ditunjukan dalam tabel uji hubungan variabel antar konstruk dapat disimpulkan bahwa loyalitas bepengaruh signifikan terhadap kinerja pegawai. Hal ini dibukktikan $\mathrm{P}$ value $<0,05$ (0.000), $\mathrm{T}$ Statistik > T Tabel $(5,597>1.996)$.

Diterimanya hipotesis pertama yaitu loyalitas berpengaruh signifikan terhadap kinerja pegawai. Tingkat loyaltas yang tinggi dan memberikan efek peningkatan kinerja secara otomatis. Pegawai yang merasa setia, aman dan nyaman dapat menumbuhkan jiwa loyalitasnya. Jika pegawai memiliki jiwa loyalita yang sangat tinggi maka pegawai tersebut akan semakin pula meningkatkan kinerjanya.

Hal ini mendukung penelitian dari (Rindyantama \& Astuti, 2017) mengatakan bahwa loyalitas berpengaruh terhadap kinerja karyawan. Kinerja karyawan dapat diukur melalui tingkat loyalitas karyawan. Semakin tinggi kesetian karyawan maka karyawn tersebut akan berlomba untuk mendapatkan prestasi. Prestasi ini dihasilkan dengan kinerja pegawai. 
Peneitian juga selaras dengan penelitian dari (Letsoin \& Ratnasari, 2020) bahwa loyalitas berpengaruh terhadap kinerja karyawan. Karyawan yang baik akan berlomba-lomba untuk menggapai prestasi dalam perusahaan. Dengan penggapaian prestasi ini dapat menumbuhkan kinerja dalam diri karyawan tersebut dengan demikian loyalitas akan terbentuk dengan sendirinya

\section{KESIMPULAN}

\section{Kesimpulan}

Penelitian ini bertujuan untuk menganalisis pengaruh kepemimpinan dan loyalitas terhadap kinerja pegawai di PLN Unit Induk Distribusi Jawa Timur Berdasarkan analisis dan pembahasan pada bagian sebelumnya, maka dapat ditarikkesimpulan sebagai berikut :

1) Gaya kepemimpinan yang memberikan pengaruh sangat baik dalam peningkatan kinerja pegawai. Pegawai akan mudah berprestasi dan mudah meningkatkan kinerjanya jika pihak pimpinan atau manajermemiliki sifat baik, tegas dan tidak semena-mena terhadap pegawai.

2) Loyalitas karyawan memberikan pengaruh dalam peningkatan kinerja. Hal ini berarti karyawan yang memiliki loyalitas yang tinggi terhadap perusahaan secara otomatis akan meningkatkan kinerja secaralangsung.

\section{Saran}

Berdasarkan keterbatasan dalam penelitian ini, diharapkan:

1) Diharapkan para pegawai dapat meningkatkan kinerja pegawai yang berguna untukmencapai tujuan perusahaan. Pemimpin dapat memberikan stigma dan motivasi agar karyawan dapt meningkatkan kinerjanya

2) Diharapkan para pegawai PT PLN UID Jatim selalu menjaga kualitas dirinya dan berupaya meningkat kualitas dirinya melalui loyalitas terhadap peusahaan agar mecapai kinerja pegawai yang diharapkan.

3) Diharapakan para manajer PT PLN dapat membina pegawai agar dapat mencapai kinerja yang diharapkan oleh perushaaan yang berguna dalam mencapai tujuan perusahaaan

\section{DAFTAR PUSTAKA}

Ahmadi, S., \& Sulistyono, S. (2019). Pengaruh Kompetensi, Kepemimpinan, Dan Disiplin Kerja Terhadap Kinerja Pegawai Di Kantor Pertanahan Kabupaten Bogor. Jurnal Manajemen Kewirausahaan, 15(2), 203-210.

Ashori, S. (2020). Pengaruh Gaya Kepemimpinan Dan Budaya Organisasi Terhadap Kinerja Karyawan Di Bprs Al-Mabrur Ponorogo. IAIN Ponorogo.

Basna, F. (2016). Analisis Gaya Kepemimpinan, Kepuasan Kerja, Komitmen Organisasi dan Kompetensi terhadap Kinerja Pegawai. Jurnal Riset Bisnis Dan Manajemen, 4(3).

Ghozali, I. (2013). Aplikasi Analisis Multivariat dengan Program IBM SPSS. Edisi 7. Semarang: Penerbit Universitas Diponegoro.

Haikal, A. (2017). Fungsi Manajemen Sumber Daya Manusia Guna Meningkatkan Kefektifan SDM pada BSI TV. Ejournalbsi.Ac.Id.

Hasibuan, M. S. P., \& Hasibuan, H. M. S. P. (2016). Manajemen sumber daya manusia. Bumi Aksara.

Letsoin, V. R., \& Ratnasari, S. L. (2020). Pengaruh Keterlibatan Karyawan, Loyalitas Kerja Dan Kerjasama Tim Terhadap Kinerja Karyawan. JURNAL DIMENSI, 9(1), 17-34. 
Marjaya, I., \& Pasaribu, F. (2019). Pengaruh Kepemimpinan, Motivasi, Dan Pelatihan Terhadap Kinerja Pegawai. Maneggio: Jurnal Ilmiah Magister Manajemen, 2(1), 129-147.

Nurlaila, N. (2010). Manajemen Sumber Daya Manusia I. Pekanbaru: Yayasan Aini Syam.

Ramadhany, D. (2017). Pengaruh Gaya Kepemimpinan Terhadap Kinerja Karyawan. 5(2), 284 288.

Rindyantama, A. F., \& Astuti, R. J. (2017). Pengaruh Gaya Kepemimpinan, Loyalitas Karyawan, Dan Beban Kerja Terhadap Kinerja Karyawan (Studi pada Guru dan Karyawan UPT SMAN Nawangan Pacitan). Jurnal Manajemen Bisnis, 8(1), 52-81.

Rosalina, M., \& Wati, L. N. (2020). PENGARUH GAYA KEPEMIMPINAN TERHADAP DISIPLIN KERJA DAN DAMPAKNYA TERHADAP KINERJA KARYAWAN. Jurnal Ekobis: Ekonomi Bisnis \& Manajemen, 10(1), 18-32. 